\title{
Acute Kidney Injury after On-pump Coronary Artery Bypass Graft Surgery
}

\author{
Maurício de Nassau Machado, Rafael Carlos Miranda, Isabela Thomaz Takakura, Eduardo Palmegiani, Carlos Alberto \\ dos Santos, Marcos Aurélio Oliveira, Osana M. Mouco, Mauro E. Hernandes, Maria Angélica Lemos, Lília N. Maia \\ Hospital de Base da Faculdade de Medicina de São José do Rio Preto - FAMERP, São José do Rio Preto, SP, Brasil
}

\section{Summary}

Background: The acute kidney injury (AKI) is a complex disease for which there is no accepted standard definition nowadays. The Acute Kidney Injury Network (AKIN) represents an attempt to standardize the criteria for diagnosis and staging of acute renal dysfunction based on recently published RIFLE criteria, that means, (Risk, Injury, Failure, Loss, and End-stage kidney disease).

Objectives: To evaluate the incidence and associated mortality of AKI in patients submitted to on-pump coronary artery bypass graft surgery (on-pump CABG).

Methods: A total of 817 patients were divided into two groups: negative AKI (-), with 421 patients (51.5\%), and positive AKI (+), with 396 patients $(48.5 \%)$. Increase of $0.3 \mathrm{mg} / \mathrm{dL}$ in creatinine or of $50 \%$ in creatinine's basal value was considered as AKI.

Results: The rate of patient's mortality with or without AKI within 30 days after cardiac surgery was $12.6 \%$ and $1.4 \%$, respectively $(\mathbf{p}<\mathbf{0 . 0 0 0 1})$. In a multivariate logistic regression model, AKI after on-pump CABG was an independent predictor of death within 30 days $(O R=6.7 ; p=0.0002)$. This group of patients presented a longer period of permanency in intensive care unit (ICU) [median 2 days ( 2 to 3 ) versus 3 days ( 2 to 5 ); $p=0.0001$ ] and a bigger proportion of patients with prolonged permanence in intensive care $(>14$ days) $(14$ versus $2 \% ; p=0.0001)$.

Conclusion: In the studied population, even a discrete alteration in renal function, based on AKIN criteria, was an independent predictor of death in 30 days after on-pump CABG. (ClinicalTrials.gov Registry: NCT00780845).

Key Words: Renal Insufficiency, Acute; Myocardial Revascularization; Extracorporeal Circulation; Mortality.

\section{Introduction}

The acute kidney injury (AKI) is a complex syndrome, which occurs in many situations and with manifestations that vary from a small increase in serum creatinine $(\mathrm{SCr})$ to the anuric renal insufficiency. Clinic results may be total recover or even death, including the development of chronic renal disease that may evolve to dependence on dialysis. AKI is a common complication in patients in serious disease status, which generates a raise in hospital costs ${ }^{1}$ and is associated with high mortality rates, that is, it is an independent predictor of risk of death ${ }^{2,3}$.

Despite the advances in the treatment and knowledge of this disease, many aspects in this field remain controversial, confuse and without consensus. Over 30 different definitions have been used in literature, making comparisons difficult ${ }^{4,5}$.

Mailing Address: Maurício de Nassau Machado •

Rua José Elias Abud, 242 - Tarraf II - 15092-490 - São José do Rio Preto, SP, Brasil

E-mail: nassau@cardiol.br

Manuscript received November 12, 2008; revised manuscript received January 28, 2009; accepted April 04, 2009.
After cardiac surgery, AKI may occur in up to $41.3 \%$ of patients, with a rate of $9.6 \%$ of necessity of dialysis (particularly in patients with preoperative renal dysfunction $)^{6}$. Hospital mortality rate is close to $1 \%$ when there is no aggravation in renal function. When there are moderate alterations, this rate may be around $20 \%$, and when there is a need of dialysis, it may exceed $50 \%^{7-10}$.

Efforts to achieve a consensus on the AKI definitions led to the formation of International Acute Kidney Injury Network (AKIN). This new definition for AKI was developed in accordance to the five-step classification known by the acronym RIFLE (Risk, Injury, Failure, Loss, and End-stage kidney disease $)^{4}$, which is based on SCr alterations and/ or urinary debt, and that divides AKI into three categories, according to gravity, and into two categories that reflect the persistence of renal function loss. Consistent with the AKIN criteria, the increase higher than or equal to $0.3 \mathrm{mg} / \mathrm{dL}$ in $\mathrm{SCr}$ or an increase of $50 \%$ in its basal value (within a period of at least 48 hours) characterize AKI.

The objective of this paper was to evaluate, founded on AKIN criteria, the incidence of clinical complications and death occurrences associated with AKI in patients that underwent onpump coronary artery bypass graft surgery (on-pump CABG). 


\section{Methods}

\section{Subjects selection}

In an open and consecutive study, 1,151 patients submitted to myocardial revascularization were evaluated in the period of January 2003 to January 2008. Data were prospectively obtained through search in electronic databases, with retrospective assessment of the variables. The present study was approved by the local Research Ethics Committee and registered in the website ClinicalTrials.gov (NCT00780845).

The change in $\mathrm{SCr}$ was defined as the difference between admission creatinine (immediate post-operative period) and the highest value obtained during the patient's permanence in the intensive care unit (ICU).

The patients were divided into two groups, according to their renal function and based on the AKIN classification:

- normal renal function, or AKI (-): patients without AKI after on-pump CABG;

- acute kidney injury, or AKI (+): patients with an increase higher than or equal to $0.3 \mathrm{mg} / \mathrm{dL}$ in SCr levels, or increase in the $\mathrm{SCr}$ higher than or equal to $50 \%$ in its basal value within a period of at least 48 hours $^{11}$.

The assessed variables were: mortality within 30 days, prolonged permanence in ICU and complications such as atrial fibrillation, reintubation due to pulmonary aggravations, prolonged mechanic ventilation (>24 hours), deep surgical site infection (Mediastinal infection) and type I neurological dysfunction. The preoperative estimation for risk of hospital death was calculated by means of the Logistic EuroSCORE ${ }^{12,13}$.

\section{Serum creatinine dosage}

Dosage of SCr was made by means of Jaffé colorimetric method (ADVIA ${ }^{\mathrm{TM}}$ 1650, Bayer). The reference values for adults are: 0.6 to $1.3 \mathrm{mg} / \mathrm{dL}$ for men, and 0.6 to $1.0 \mathrm{mg} / \mathrm{dL}$ for women.

\section{Definition of the complications}

The following occurrences were defined as post-operative clinical complications:

- cardiac arrhythmias: acute atrial fibrillation that last more than one hour;

- reintubation due to pulmonary complications: tracheal reintubation due to respiratory insufficiency that results from alterations in respiratory mechanics or respiratory infection (tracheobronchitis or pneumonia);

- mediastinal infection: mediastinal secretion associated with clinical signs of infection (fever, leukocytosis, thoracic pain) with or without sternal instability and with secretions culture or positive hemoculture during the first 30 postoperative days;

- type I neurological lesion: new and persistent focal motor deficit, coma, seizure or encephalic lesion documented by cranium computed tomography or magnetic resonance imaging;

- death: all-cause mortality within 30 days after surgery.

\section{Inclusion criteria}

Patients submitted to on-pump CABG and patients who had at least two dosages of $\mathrm{SCr}$ after surgery, within at least 48 hours.

\section{Exclusion criteria}

Carriers of terminal chronic renal disease and that were under dialysis treatment previously to the cardiac surgery.

\section{Statistical analysis}

Categorical data are presented in absolute numbers and percentage, while continual variables are presented in mean \pm standard deviation (SD) or median and interquartil range. Continual variables of the groups were compared by means of Mann-Whitney non-parametric test. The chi-square or Fisher's exact test was used for the comparison of categorical variables. Kaplan-Meier curves were constructed for mortality within 30 days, and the $p$-values were calculated through Long-Rank and Wilcoxon tests.

Presence of AKI was determined and compared through the analysis of Receiver Operating Characteristic (ROC) curve for mortality within 30 days. An area of 1.0 under the ROC curve indicates perfect discrimination, for an area of 0.5 indicates that the result of the test is not better than chance. Areas of 0.5 to 0.7 suggest low predictive discrimination, and values higher than 0.7 confirm the utility of the model as a risk predictor ${ }^{14}$. Confidence interval $(\mathrm{Cl})$ of the area under the ROC curve was calculated through Wilcoxon test.

Multivariate logistic regression model was used to determine the independent predictors of death. Odds Ratio and 95\% confidence interval $(95 \% \mathrm{Cl})$ were calculated in the main clinical complications and for death through a comparison of patients with normal function to patients with $\mathrm{AKI}$, based on AKIN classification.

The values of $p<0.05$ were considered statistically significant (bicaudals). The software Stats Direct Statistics v. 2.5.8 was used for the analysis.

\section{Results}

Among the 1,151 assessed patients, 817 (71\%) underwent surgery with extracorporeal circulation. Patient's mean age was $61 \pm 9$ years, and 567 of them (70\%) were males. Median EuroSCORE was 1.8 (1.2 a 3.0). Criteria for AKI diagnosis, based on AKIN classification, were fulfilled by 396 patients (48.5\%), and 31 patients (3.8\%) needed dialysis. The patients who presented AKI were mainly old-aged (60 versus 62 years old), had higher diabetes mellitus rates (31 versus $39 \%$ ) and had a larger proportion of female gender. There were no statistically significant differences between groups in extracorporeal circulation duration (Table 1). The mean creatinine increase rate was $21 \%$ in AKI group (-) versus $61 \%$ in AKI group (+). Patients who evolved AKI in the post-operative period had basal values in the second day of this phase and maximum creatinine values that were higher than those of the patients without AKI (Table 2).

Median permanence period in ICU was 2 versus 3 days, and a bigger proportion of $\mathrm{AKI}(+)$ patients had prolonged 


\section{Original Article}

\section{Table 1 - Base characteristics of patients}

\begin{tabular}{lccc}
\hline Base characteristics & $\begin{array}{c}\text { AKI (-) } \\
\mathrm{n}=421\end{array}$ & $\begin{array}{c}\text { AKI (+) } \\
\mathrm{n}=396\end{array}$ & p-value \\
\hline Males $-\mathrm{n}(\%)$ & $309(73.4)$ & $258(65.2)$ & 0.013 \\
\hline Age (mean $\pm \mathrm{SD})$ & $60.3 \pm 9.5$ & $61.7 \pm 9.1$ & 0.039 \\
\hline BMI (mean \pm SD) & $27.4 \pm 4.1$ & $26.8 \pm 4.3$ & 0.071 \\
\hline Diabetes mellitus $-\mathrm{n}(\%)$ & $130(30.9)$ & $154(38.9)$ & 0.020 \\
\hline $\begin{array}{l}\text { Moderate/severe left } \\
\text { ventricle dysfunction }-\mathrm{n}(\%)\end{array}$ & $112(26.6)$ & $108(27.3)$ & 0.891 \\
\hline $\begin{array}{l}\text { Usage of intra-aortic } \\
\text { balloon pump - } \mathrm{n}(\%)\end{array}$ & $28(6.7)$ & $28(7.1)$ & 0.921 \\
\hline $\begin{array}{l}\text { Duration of extracorporeal } \\
\text { circulation (mean } \pm \mathrm{SD})\end{array}$ & $95.4 \pm 23.5$ & $96.2 \pm 25.4$ & 0.646 \\
\hline $\begin{array}{l}\text { Number of distal grafts }- \\
\text { median (min. and max.) }\end{array}$ & $3(1$ to 5$)$ & $3(1$ to 5$)$ & 0.703 \\
\hline $\begin{array}{l}\text { Logistic EuroScore - } \\
\text { median (Q1-Q3) }\end{array}$ & $1.7(1.1-2.7)$ & $2(1.2-3.3)$ & 0.002 \\
\hline
\end{tabular}

$A K I$ - acute kidney injury; $n=$ number of patients; $S D$ - standard deviation; BMI - body mass index; min. - minimum value; max. - maximum value; $Q 1$ - $25^{\text {th }}$ percentile; Q3 - $75^{\text {th }}$ percentile.

Table 2 - Analysis of creatinine values

\begin{tabular}{lccc}
\hline Creatinine & $\begin{array}{c}\text { AKI }(-) \\
\mathrm{n}=421\end{array}$ & $\begin{array}{c}\text { AKI }(+) \\
\mathrm{n}=396\end{array}$ & p-value \\
\hline $\begin{array}{l}\text { Admission creatinine } \\
\text { (mean } \pm \text { SD) }\end{array}$ & $1.21 \pm 0.30$ & $1.35 \pm 0.50$ & $<0.0001$ \\
\hline $\begin{array}{l}\text { Creatinine in second post- } \\
\text { operative day (mean } \pm S D)\end{array}$ & $1.05 \pm 0.30$ & $1.41 \pm 0.87$ & $<0.0001$ \\
\hline $\begin{array}{l}\text { Highest creatinine level } \\
\text { (mean } \pm S D)\end{array}$ & $1.26 \pm 0.31$ & $2.10 \pm 1.35$ & $<0.0001$ \\
\hline $\begin{array}{l}\text { Increase in creatinine } \\
\text { (highest level/basal level) }(\%)\end{array}$ & $21 \pm 14.0$ & $61 \pm 77.0$ & $<0.0001$ \\
\hline
\end{tabular}

$A K I$ - acute kidney injury; $n$ - number of patients; SD - standard deviation.

permanence in intensive care (>14 day), 14 versus $2 \%$. Mortality rate within 30 days for AKI (+) patients was $12.6 \%$ in comparison to $1.4 \%$ for AKI $(-)$ patients $(p<0.0001$; approximate power for $5 \%$ statistical significance $>99.9 \%$ and population attributable risk of 79\%) (Table 3, Graphic 1). The area under ROC curve for AKI and death corresponded to $0.72(95 \% \mathrm{Cl}=0.67-0.76)$, with $89 \%$ of sensibility, $54 \%$ of specificity, positive predictive value of $13 \%$ and negative predictive value of $99 \%$ (Graphic 2). In a multivariate logistic regression model, $\mathrm{AKI}$ in the post-operative period was an independent predictor of death within 30 days (Odds Ratio: $6.7 ; p=0.0002$ ) (Table 4). Patients who needed dialysis (3.8\%) had a $55 \%$ mortality rate.
Table 3 - Clinical complications after on-pump CABG

\begin{tabular}{|c|c|c|c|}
\hline Clinical complications & $\begin{array}{l}\text { AKI (-) } \\
n=421\end{array}$ & $\begin{array}{l}\text { AKI (+) } \\
n=396\end{array}$ & p-value \\
\hline $\begin{array}{l}\text { Period of treatment in intensive } \\
\text { care unit - median (Q1 e Q3) }\end{array}$ & 2 (2 to 3 ) & $3(2$ to 5$)$ & $<0.0001$ \\
\hline $\begin{array}{l}\text { Readmission in intensive } \\
\text { care unit - } \mathrm{n}(\%)\end{array}$ & $7(1.7)$ & $33(8.3)$ & $<0.0001$ \\
\hline $\begin{array}{l}\text { Permanence in intensive } \\
\text { care unit }>14 \text { dias }-n(\%)\end{array}$ & $8(1.9)$ & $56(14.1)$ & $<0.0001$ \\
\hline $\begin{array}{l}\text { Reintervention due to bleeding } \\
-\mathrm{n}(\%)\end{array}$ & $3(0.7)$ & $14(3.5)$ & 0.01 \\
\hline Atrial fibrillation $-\mathrm{n}(\%)$ & $26(6.2)$ & $61(15.4)$ & $<0.0001$ \\
\hline $\begin{array}{l}\text { Reintubation due to pulmonary } \\
\text { complications - } n(\%)\end{array}$ & $14(3.3)$ & $71(17.9)$ & $<0.0001$ \\
\hline $\begin{array}{l}\text { Mechanic ventilation }>24 \text { hours } \\
-n(\%)\end{array}$ & $18(4.3)$ & $77(19.4)$ & $<0.0001$ \\
\hline Dialysis & $0(0)$ & $31(7.8)$ & $<0.0001$ \\
\hline Type I neurological lesion - $n(\%)$ & $11(2.6)$ & $26(6.6)$ & 0.01 \\
\hline Death within 30 days $-\mathrm{n}(\%)$ & $6(1.4)$ & $50(12.6)$ & $<0.0001$ \\
\hline
\end{tabular}

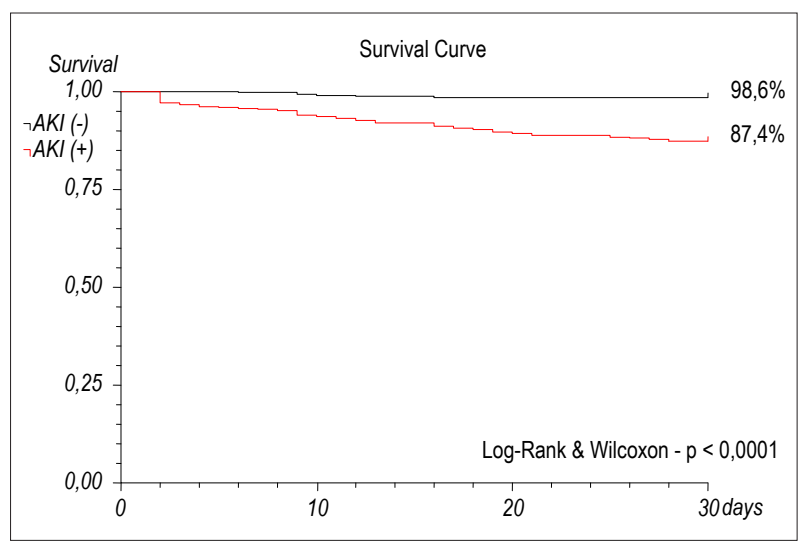

Graphic 1 - Kaplan-Meier curve for survival within 30 days.

Subgroup analysis demonstrated that the manifestation of $\mathrm{AKI}$ in post-operative period was an independent predictor of death within 30 days (Table 4) for patients with normal basal SCr (males $\leq 1.3 \mathrm{mg} / \mathrm{dL}$ and females $\leq 1.0 \mathrm{mg} / \mathrm{dL}$ ) as much as for those with altered SCr (males $\geq 1.4 \mathrm{mg} / \mathrm{dL}$ and females $\geq 1.1 \mathrm{mg} / \mathrm{dL}$ ).

In the normal basal SCr patients subgroup, prevalence of AKI was $40 \%$ and mortality rate within 30 days was 11.2 versus $1.1 \%$ ( $p<0.0001$; approximate power for $5 \%$ statistical significance of $99 \%$ and population attributable risk of $78 \%$ ). AKI prevalence in patients with altered basal SCr was of 59\%, with mortality rate of 14 versus $2 \%$ in the patients without post-operative AKI $(p<0.0001$; approximate power for $5 \%$ 
statistical significance of $98 \%$ and population attributable risk of $78 \%$ ).

In the multivariate logistic regression model, only AKI and mechanic ventilation $>24$ hours were independent predictors of death in global analysis as much as in the subgroups analyses (Table 4).

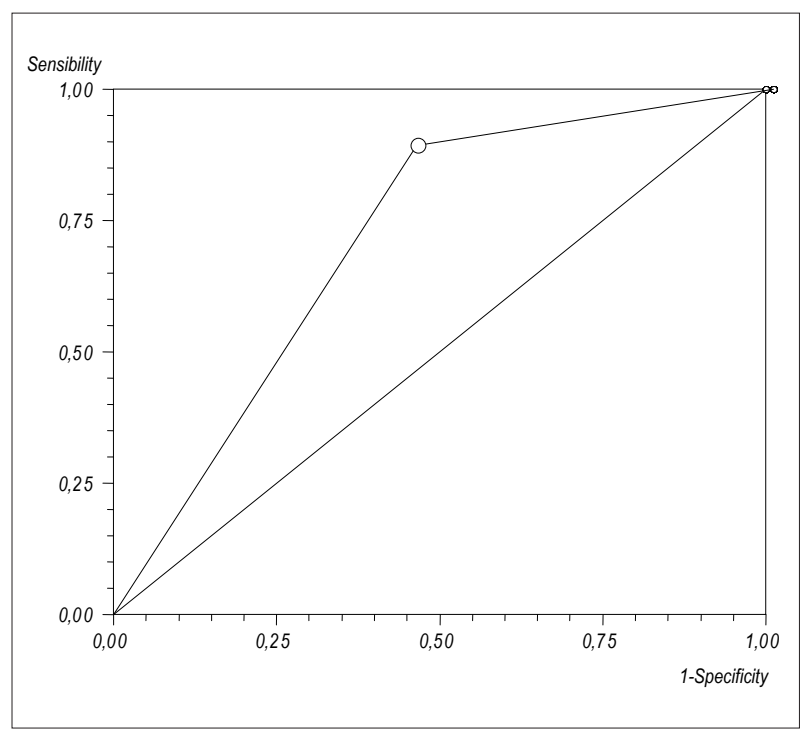

Graphic 2 - Receiver operating characteristic (ROC) curve: accuracy of acute kidney injury for death within 30 days. Sensibility Specificity. Area under ROC curve $=0.72(95 \% \mathrm{Cl}=0.67-0.76) ;$ Sensibility $=89 \%(95 \% \mathrm{Cl}=78-96 \%) ;$ Specificity $=54 \%(95 \% \mathrm{Cl}=51-58 \%) ;$ Positive predictor value $=13 \%$; Negative predictor value $=99 \%$

\section{Discussion}

After cardiac surgery and depending on the base criteria, AKI may occur in up to $41.3 \%$ of patients, with a rate of $9.6 \%$ of need of dialysis (mainly patients with preoperative renal lesion) ${ }^{6}$. Hospital mortality is close to $1 \%$ when there is no renal function aggravation, is close to $20 \%$ with moderate alterations in renal function and exceeds $50 \%$ when dialysis is required $7,9,10,15,16$.

AKI is a complex clinical status and has heterogeneous etiology, which makes nephrologists and intensivists discuss the necessity of diagnosis, staging and prognosis standardization. An ideal classification for AKI should have high accuracy and be predictor of relevant clinical results and mortality. Many papers on severely sick patients ${ }^{15,17}$ and patients submitted to cardiac surgery ${ }^{1,18-20}$ have been published in an attempt to validate these criteria.

In this study, we observed that the AKIN classification may be easily applied to patients submitted to cardiac surgery. According to this staging, $48.5 \%$ of the patients fulfilled the criteria for AKI diagnosis, which shows a prevalence that is higher than those found in other publications. In spite of the application of the same diagnosis criteria, the AKI rates may vary considerably, ranging from 6.9 to $42.5 \%$ of incidence ${ }^{1,21}$. Mortality rate of the studied AKI patients was high (12.6\%), reaching 55\% among the patients who needed dialysis (in contrast to $1.4 \%$ of death occurrences in patients without $\mathrm{AKI})$. Despite the higher rates of $\mathrm{AKI}$ $(59 \%)$ and mortality (14\%) in patients with altered basal $\mathrm{SCr}$, the patients who had their renal function maintained in the post-operative period presented low mortality rate $(2 \%)$, as shown in other studies ${ }^{6,22}$.

Table 4 - Multivariate logistic regression model: independent predictor of death after on-pump CABG

\begin{tabular}{|c|c|c|c|c|c|c|c|c|c|}
\hline \multirow{2}{*}{ Death predictors } & \multicolumn{3}{|c|}{$\begin{array}{l}\text { All patients } \\
\qquad(n=817)\end{array}$} & \multicolumn{3}{|c|}{$\begin{array}{l}\text { Normal basal SCr* } \\
\quad(n=448)\end{array}$} & \multicolumn{3}{|c|}{$\begin{array}{l}\text { Altered basal } \mathrm{SCr}^{\dagger} \\
\qquad(\mathrm{n}=369)\end{array}$} \\
\hline & OR & $95 \% \mathrm{Cl}$ & $\mathrm{p}$-value & OR & $95 \% \mathrm{Cl}$ & $\mathrm{p}$-value & OR & $95 \% \mathrm{Cl}$ & $\mathrm{p}$-value \\
\hline Age & 1.1 & 0.9 to 1.1 & 0.389 & 1.0 & 0.9 to 1.1 & 0.305 & 1.0 & 0.9 to 1.1 & 0.417 \\
\hline $\mathrm{BMI}$ & 0.9 & 0.8 to 1.0 & 0.079 & 0.8 & 0.7 to 0.9 & 0.004 & 1.0 & 0.9 to 1.1 & 0.890 \\
\hline Readmission in ICU & 4.8 & 1.6 to 14.9 & 0.006 & 12.0 & 1.1 to 125.7 & 0.037 & 3.7 & 0.9 to 15.5 & 0.071 \\
\hline Acute kidney injury & 6.7 & 2.5 to 18.2 & 0.0002 & 10.4 & 2.0 to 57.0 & 0.007 & 5.2 & 1.2 to 22.5 & 0.026 \\
\hline Duration of ECC & 1.0 & 0.9 to 1.0 & 0.079 & 1.0 & 1.0 to 1.1 & 0.077 & 1.0 & 1.0 to 1.0 & 0.280 \\
\hline Reintervention due to bleeding & 1.1 & 0.3 to 4.4 & 0.935 & 0.4 & 0.1 to 6.5 & 0.519 & 3.0 & 0.5 to 18.5 & 0.225 \\
\hline Respiratory infection & 2.0 & 0.8 to 5.0 & 0.147 & 2.5 & 0.4 to 16.7 & 0.300 & 1.4 & 0.4 to 4.6 & 0.578 \\
\hline $\begin{array}{l}\text { Reintubation due to pulmonary } \\
\text { complications }\end{array}$ & 1.9 & 0.7 to 5.3 & 0.216 & 0.2 & 0.1 to 1.8 & 0.162 & 4.2 & 1.1 to 15.8 & 0.033 \\
\hline Mechanic ventilation $>24$ hours & 11.3 & 3.7 to 33.9 & $<0.0001$ & 71.3 & 8.0 to 636.7 & 0.0001 & 8.6 & 2.1 to 35.6 & 0.003 \\
\hline Mediastinal infection & 0.4 & 0.1 to 1.9 & 0.248 & 0.5 & 0.1 to 9.7 & 0.625 & 0.5 & 0.1 to 3.5 & 0.505 \\
\hline Type I neurological lesion & 1.5 & 0.6 to 4.1 & 0.382 & 7.5 & 1.3 to 42.6 & 0.023 & 0.6 & 0.1 to 2.4 & 0.467 \\
\hline
\end{tabular}

SCr - serum creatinine; OR - Odds Ratio; Cl - confidence interval; BMI - body mass index; ICU - intensive care unit; $E C C$ - extracorporeal circulation; $n=n u m b e r$ of patients. *Normal basal SCr: males $\leq 1.3 \mathrm{mg} / \mathrm{dL}$ and females $\leq 1.0 \mathrm{mg} / \mathrm{dL}$; taltered basal SCr: males $\geq 1.4 \mathrm{mg} / \mathrm{dL}$ and females $\geq 1.1 \mathrm{mg} / \mathrm{dL}$. 


\section{Original Article}

These new recommendations on the AKI diagnosis have not been largely tested and evaluated thus far. Studies in the intensive care sphere have demonstrated their value with regard to clinical results and to the increase of mortality rate $^{17,23,24}$. In cardiac surgery, as AKI represents an important clinical complication, RIFLE and AKIN classifications have shown high-accuracy detection of patients in risk of higher clinical complications, increase in hospital costs and death at short term ${ }^{1,18-20,25}$

After evaluating a database of 41,972 patients admitted in 22 ICU of the United Kingdom and Germany, from 1989 to 1999 , Ostermann et al $^{15}$ demonstrated the AKI incidence based on the $35.8 \%$ RIFLE classification (risk: $17.2 \%$; injury: $11 \%$ and failure: $7.6 \%$ ) with mortality rates of $20.9,45.6$ and $56.8 \%$, respectively. Among patients who did not develop AKI, the mortality rate was $8.4 \%$.

Bagshaw et $\mathrm{al}^{17}$ assessed information of 120,123 patients admitted for more than 24 hours in 57 ICU throughout Australia (Australian New Zealand Intensive Care Society Adult Patient Database) in a heterogeneous group of patients severely sick. According to RIFLE classification applied at patient's admission, AKI was present in $36.1 \%$ of them (risk: $16.3 \%$; injury: $13.6 \%$ and failure: $6.3 \%$ ) with a mortality rate of $17.9,27.7$ and $33.2 \%$, respectively. In the multivariate analysis, each RIFLE category was independently associated with hospital mortality (Odds Ratio: risk: 1.58; injury: 2.54 and failure: 3.22 ).

After evaluating 813 patients submitted to cardiac surgery, Kuitunen et $\mathrm{a}^{20}$ found $19.3 \%$ of patients with AKI based on RIFLE classification. Patients with severe renal lesion, RIFLE-F (failure), had mortality rate of $32.5 \%$ within 90 days in comparison to $8 \%$ with RIFLE-R (risk) and $21.4 \%$ with RIFLE-I (injury). Patients without AKI showed mortality rate of $0.9 \%$. In a multivariate logistic regression model, the RIFLE classification was an independent mortality predictor within 90 days.

New markers, such as cystatin C, interleukin-18, Kidney Injury Molecule-1 (KIM-1) e Neutrophil Gelatinase-Associated Lipocalin (NGAL), have been tested for precocious detection of $\mathrm{AKI}$ patients ${ }^{26}$, but their utility and/or superiority are still to be proven.

Clearly, this study demonstrates that even discrete alterations in renal function, taking into account the AKIN criteria, are independent predictors of death within 30 days after on-pump coronary artery bypass graft surgery (onpump CABG) in patients with normal basal SCr, as much as in those with altered basal SCr. The percentage $(\geq 50 \%)$ or absolute $(\geq 0.3 \mathrm{mg} / \mathrm{dL}$ ) increase in $\mathrm{SCr}$ remain as a powerful renal function assessment instrument in patients submitted to cardiac surgery.

\section{Conclusion}

In the studied population, even a discrete alteration in renal function was an independent predictor of death within 30 days, as taken into account the AKIN classification. This group of patients presented higher permanence and prolonged stay rates in ICU (>14 days) and also a bigger proportion of clinical complications in the post-operative period.

\section{Acknowledgments}

The authors would like to thank the multidisciplinary team and, above all, the health professionals of the post-operative care unit for cardiac surgery, for the execution of this paper would not have been possible without their support.

\section{Potential Conflict of Interest}

No potential conflict of interest relevant to this article was reported.

\section{Sources of Funding}

There were no external funding sources for this study.

\section{Study Association}

This study is not associated with any post-graduation program.

\section{References}

1. Dasta JF, Kane-Gill SL, Durtschi AJ, Pathak DS, Kellum JA. Costs and outcomes of acute kidney injury (AKI) following cardiac surgery. Nephrol Dial Transplant. 2008; 23 (6): 1970-4.

2. Chertow GM, Levy EM, Hammermeister KE, Grover F, Daley J. Independent association between acute renal failure and mortality following cardiac surgery. JAMA. 1998; 104: 343-8.

3. de Mendonca A, Vincent JL, Suter PM, Moreno R, Dearden NM, Antonelli $M$, et al. Acute renal failure in the ICU: risk factors and outcome evaluation by SOFA score. Intensive Care Med. 2000; 26: 915-21.

4. Bellomo R, Ronco C, Kellum JA, Mehta RL, Palevsky P, Acute Dialysis Quality Initiative Workgroup. Acute renal failure - definition, outcome measures, animal models, fluid therapy and information technology needs: the Second International Consensus Conference of the Acute Dialysis Quality Initiative (ADQI) Group. Crit Care. 2004; 8 (4): R204-R212.

5. Lameire N, Hoste E. Reflections on the definition, classification, and diagnostic evaluation of acute renal failure. Curr Opin Crit Care. 2004; 10(6):468-75.

6. Yehia M, Collins JF, Beca J. Acute renal failure in patients with pre-existing renal dysfunction following coronary artery bypass grafting. Nephrology (Carlton). 2005; 10 (6): 541-3.

7. Mangano CM, Diamondstone LS, Ramsay JG, Aggarwal A, Herskowitz A, Mangano DT. Renal dysfunction after myocardial revascularization: risk factors, adverse outcomes, and hospital resource utilization. The Multicenter Study of Perioperative Ischemia Research Group. Ann Intern Med. 1998; 128 (3): 194-203.

8. Ostermann ME, Taube D, Morgan CJ, Evans TW. Acute renal failure following cardiopulmonary bypass: a changing picture. Intensive Care Med. 2000; 26 (5): 565-71. 
9. Bahar I, Akgul A, Ozatik MA, Vural KM, Demirbag AE, Boran M, et al. Acute renal failure following open heart surgery: risk factors and prognosis. Perfusion. 2005; 20 (6): 317-22.

10. Landoni G, Zangrillo A, Franco A, Aletti G, Roberti A, Calabro MG, et al. Long-term outcome of patients who require renal replacement therapy after cardiac surgery. Eur J Anaesthesiol. 2006; 23 (1): 17-22.

11. Mehta RL, Kellum JA, Shah SV, Molitoris BA, Ronco C, Warnock DG, et al. Acute kidney injury network: report of an initiative to improve outcomes in acute kidney injury. Crit Care. 2007; 11 (2): R31.

12. Nashef SA, Roques F, Michel P, Gauducheau E, Lemeshow S, Salamon R. European system for cardiac operative risk evaluation (EuroSCORE). Eur J Cardiothorac Surg. 1999; 16 (1): 9-13.

13. Roques F, Nashef SA, Michel P, Gauducheau E, de Vincentiis C, Baudet E, et al. Risk factors and outcome in European cardiac surgery: analysis of the EuroSCORE multinational database of 19030 patients. Eur J Cardiothorac Surg. 1999; 15 (6): 816-22.

14. Swets JA. Measuring the accuracy of diagnostic systems. Science. 1988; 240: 1285-93.

15. Ostermann M, Chang RW. Acute kidney injury in the intensive care unit according to RIFLE. Crit Care Med. 2007; 35 (8): 1837-43.

16. Santos FO, Silveira MA, Maia RB, Monteiro MD, Martinelli R. Acute renal failure after coronary artery bypass surgery with extracorporeal circulation -- incidence, risk factors, and mortality. Arq Bras Cardiol. 2004; 83 (2): 150-4.

17. Bagshaw SM, George C, Dinu I, Bellomo R. A multi-centre evaluation of the RIFLE criteria for early acute kidney injury in critically ill patients. Nephrol Dial Transplant. 2008; 23 (4): 1203-10.
18. Heringlake M, Knappe M, Vargas HO, Lufft H, Kindgen-Milles D, Bottige BW, et al. Renal dysfunction according to the ADQI-RIFLE system and clinical practice patterns after cardiac surgery in Germany. Minerva Anestesiol. 2006; 72 (7-8): 645-54.

19. Arnaoutakis GJ, Bihorac A, Martin TD, Hess PJ Jr, Klodell CT, Ejaz AA, et al. RIFLE criteria for acute kidney injury in aortic arch surgery. J Thorac Cardiovasc Surg. 2007; 134 (6): 1554-60.

20. Kuitunen A, Vento A, Suojaranta-Ylinen R, Pettila V. Acute renal failure afte cardiac surgery: evaluation of the RIFLE classification. Ann Thorac Surg. 2006; 81 (2): 542-6.

21. Lombardi R, Ferreiro A. Risk factors profile for acute kidney injury after cardiac surgery is different according to the level of baseline renal function. Ren Fail. 2008; 30 (2): 155-60.

22. Weerasinghe A, Hornick P, Smith P, Taylor K, Ratnatunga C. Coronary artery bypass grafting in non-dialysis-dependent mild-to-moderate renal dysfunction. J Thorac Cardiovasc Surg. 2001; 121 (6): 1083-9.

23. Bagshaw SM, George C, Bellomo R. A comparison of the RIFLE and AKIN criteria for acute kidney injury in critically ill patients. Nephrol Dial Transplant. 2008; 23 (5): 1569-74

24. Bagshaw SM, George C, Bellomo R, ANZICS Database Management Committee. Early acute kidney injury and sepsis: a multicentre evaluation. Crit Care. 2008; 12 (2): R47.

25. Massoudy P, Wagner S, Thielmann M, Herold U, Kottenberg-Assenmacher E, Marggraf $\mathrm{G}$, etal. Coronary artery bypass surgery and acute kidney injury--impact of the off-pump technique. Nephrol Dial Transplant 2008; 23 (9): 2853-60.

26. Parikh CR, Devarajan P. New biomarkers of acute kidney injury. Crit Care Med. 2008; 36 (4 Suppl): S159-65. 